\title{
4 Truth-conditional Theories of Meaning
}

Basically, there are a large number of dividing lines that can be drawn with respect to competing theories of meaning. Here, I would like to focus on just one possible divide; namely the distinctive characteristics of, on the one hand, usage-based theories and, on the other hand, truth-conditional semantics (TCS, henceforth). For the most part, I am going to concentrate on neo-Davidsonian approaches to semantics. I think, though, that most of my critical remarks concerning TCS apply equally to all similar approaches that take explanations of referential relations of linguistic expressions to be the hallmark of success in semantics. I have divided the present chapter into two sections. In the first of these two sections (4.1), I will be presenting the general idea behind truth-conditional semantics, which is, roughly speaking, that specifying a sentence's truth conditions is one way of stating its meaning. My plan is to introduce the main motivation in favour of TCS by taking a reconstruction of Davidson's famous argument concerning sentence comprehension as my starting point. I discuss this argument in detail by distinguishing between two theoretically independent issues: Novelty ${ }^{1}$ and compositionality. The former is, roughly, competent language users' ability to comprehend sentences that they have not heard before. The latter is a well-known feature of natural languages, i.e. the (apparent) fact that the semantic value of a sentence is a composition of the semantic values of its constituents.

In the second part of this chapter (4.2), I explain why TCS is supposed to be the theory that seems to fit the bill with respect to Novelty. My criti-

1 In contrast to compositionality, Novelty is a phenomenon that is seldom discussed. Whenever I refer to it, I use a capitalised word to indicate that I mean the particular characterisation that I give below. I tend to call Novelty a 'problem', which is a shorthand description for 'the problem to explain how it is possible that Novelty holds'. 
cism will be based on a detailed evaluation of arguments pro TCS. Finally, I will argue that usage-based approaches are not only also able to account for human comprehension competencies, but that they are, in fact, better suited for this purpose. This anticipates a methodological argument that I present in the third part of this book (in 7.1.1 and 7.2.2)-an argument to the effect that phenomena (as opposed to their corresponding abstractions) have epistemological primacy. Applied to language comprehension, this amounts to saying that sentence understanding can only be accounted for in terms of understanding of utterances, and not, as the truth-conditional semanticist is likely to suppose, the other way around.

\subsection{Donald Davidson et al.}

In this section, I give a short overview of truth-conditional semantics by way of presenting one highly influential argument in its favour. By far the most important figure in this area is, of course, Donald Davidson. The major part of the presentation below draws on his early writings, especially Truth and Meaning. I am going to assume for the rest of the chapter that my main target in this area is not Davidson's theory per se but what his heirs made of it, i.e. neo-Davidson semantics. Davidson's work on meaning is based on Tarski's prior work on truth in formalised languages. Accordingly, I shall briefly present this framework as well. Many more recent theories in philosophical semantics are inspired or directly influenced by Davidson's early work. However, the main idea behind Davidsonian semantics has remained unmodified since then: explaining linguistic capacities in terms of postulates that correspond to the 'rules of composition' and 'reference postulates' in a Tarski-style theory of truth. ${ }^{2}$ Therefore, I think it is safe to say that my general critique of TCS applies across the board, so to speak, although it critically engages specifically with one aspect of Davidson's original argumentation.

\footnotetext{
2 Note that in modern theories in philosophy of language and in formal semantics, the term "refers" replaces what was "fulfils" in Tarski's truth theory.
} 


\subsubsection{Introduction to the Framework}

The most relevant alternative to usage-based approaches to meaning is truth-conditional semantics. ${ }^{3}$ Its most prominent proponent is Donald Davidson, who elaborated and defended his theory of meaning in a number of articles. ${ }^{4}$ In summarising the main ideas of truth-conditional semantics, I shall mainly focus on the early Davidsonian way of presenting it. ${ }^{5}$ Why is Davidson's theory relevant for the present purposes? This is simply because TCS, in general, is a theory that is well suited to account for one specific problem: sentence comprehension. And, as will turn out in due course, this problem is particularly hard to tackle from outside truth-conditional approaches.

The problem, in short, is this: language users can understand and produce (in the respective languages that they master) a potentially unlimited number of sentences, and they do so with only limited cognitive resources (in particular, severely limited memory). The problem is how best to account for this astonishing ability. Most significantly, competent language users have (in fact, can have) only limited knowledge in regard to the meanings of atomic expressions (words, morphemes, and so on). More precisely,

3 As already indicated above, a classification system of established theories always involves some simplification. Insofar as this is true for all classifications, I am not particularly worried by the simplifications that I presuppose here. I think it is fair to say that if one puts all broadly 'usage-based' frameworks into one group, then the most obvious contrast group is theories that take reference to be the central semantic notion. In this sense, (neo-)Davidsonian semantics seems indeed the most relevant rival theory.

4 The most important essays are collected in Davidson (1985). Out of these, Truth and Meaning (Davidson 1967) is the central point of reference. Regarding his philosophy of language, Davidson (2005) is another relevant collection. Therein, the reprints that are most relevant to our present subject matter include: Davidson $(1986,1994)$. The earlier works of Davidson differ in some respects from his later work. Besides the three articles just mentioned, Davidson (1990) gives a comprehensive overview of his 'later' position.

5 The most influential neo-Davidsonians are Ernest Lepore and Kirk Ludwig (e.g. Lepore (2006), Lepore \& Ludwig $(2005,2006))$. There are some strands both in linguistics and philosophy that, although not dealing with Davidsonian philosophy itself, are heavily influenced by the core insights of truth-conditional semantics. Among others, these include: Bar-On, Horisk \& Lycan (2000), Borg (2004b, 2012a), Fodor \& Lepore (2002), Heck (2007), Lycan (2010). A very comprehensive, critical interpretation of Davidson's earlier work is Hoeltje (2012), who argues, essentially, that Davidson's conviction that a truth theory can serve as a basis for one's theory of meaning is not well justified. 
the number of meaningful atomic expressions in a given natural language is always restricted, whereas the range of propositional content that can be expressed by means of language never is. Still, competent speakers know what a given sentence means independently from whether they have heard or read this sentence before (subject to their familiarity with all constituents and the relevant syntactic structure). Here is an example that illustrates this ability:

During the 2012 Olympic Games, Boris Johnson, then mayor of London, cried out loud 'Mother is the best' before he jumped head-first into the Thames.

Chances are quite high that you never have read this sentence before. However, you are able to comprehend its content (I assume). You understand that this sentence says that during the 2012 Olympic Games, Boris fohnson, then mayor of London, cried out loud 'Mother is the best' before he jumped head-first into the Thames. Truth-conditional semantics is highly relevant for the purposes of this chapter, because it sets out to provide an explanation for this astonishing ability.

In fact, you hardly ever come across a theoretic justification of truthconditional semantics that would not refer to this specific ability. In light of this, I think it makes sense to take this as an appropriate starting point for a general discussion of the framework. For obvious reasons, this overview will be kept relatively short. ${ }^{6}$

\subsubsection{Understanding Sentences}

When it comes to truth-conditional semantics and its advantages, two issues must be kept apart. The first is the phenomenon just described: the ability of language users to comprehend potentially any novel sentence in their language. ${ }^{7}$ The other important observation that TCS accounts for is

6 For a comprehensive, in-depth analysis of Davidson's semantic programme, I refer the interested reader to Lepore (2006).

7 This holds, given some-more or less uncontroversial-background assumptions. For example, natural language sentences may be infinitely long, i.e. the recursive character of languages allows for sentences of any length. Particular sentences are always finite, though. Human beings with their limited cognitive resources, however, can only under- 
that natural languages seem to be compositional-which, from Davidson's own perspective, is just the other side of the coin. There are several ways of conceiving of compositionality, ${ }^{8}$ but the following definition will do for our purposes. A language is compositional iff the meaning of a sentence is determined by the meanings of its atomic parts (words, morphemes, ...) and the way the sentence is structured. To take a simple example: the (literal) meaning of "Snow is white" is (fully) determined by the meanings of "snow", "is", and "white" and the syntactic structure of the sentence, i.e.

stand sentences up to a certain length (depending on their memory). If one ignores these limitations for a moment, one may say that language users can potentially understand an unlimited number of sentences (all grammatical sentences of that language). Roughly put, they may in principle understand every grammatical sentence of their language. Davidson mentions some further important assumptions:

When we can regard the meaning of each sentence as a function of a finite number of features of the sentence, we have an insight not only into what there is to be learned; we also understand how an infinite aptitude can be encompassed by finite accomplishments. For suppose that a language lacks this feature; then no matter how many sentences a would-be speaker learns to produce and understand, there will remain others whose meanings are not given by the rules already mastered. It is natural to say such a language is unlearnable. This argument depends, of course, on a number of empirical assumptions: for example, that we do not at some point suddenly acquire an ability to intuit the meanings of sentences on no rule at all; that each new item of vocabulary, or new grammatical rule, takes some finite time to be learned; that man is mortal. (Davidson 1965, pp. 8-9 of the reprint)

A further issue, that I will briefly touch upon below, is that Davidson and contemporary scholars speak of sentences instead of utterances. The problem here is that, prima facie, only utterances can be understood, since they are the relevant type of entity that plays a role in understanding. On the other hand, utterances mean a variety of different things in different situations and sentence meaning is just one factor that potentially influences utterance meaning. Taken together, the most plausible reading here is that utterance comprehension always-i.e. independent from specific contexts of utterance-rests upon one's ability to comprehend the 'literal' sentential meaning first. And for this ability (neo-)Davidsonian semantics is supposed to provide the corresponding interpretations. I will return to this in 7.2.2.

8 See Gendler Szabó (2012a) for a review. See also Pagin \& Westerståhl (2010a, 2010b), who give a nice, comparatively non-technical introduction to the topic. Cf. also Fulop \& Keenan (2002), Grandy (1990), Groenendijk \& Stokhof (2005), Pelletier (1994, 2003), and Robbins (2001). For a decidedly pro-TCS argumentation in the context of compositionality, see Higginbotham (2007). 
the meaning that is, for lack of a better description, 'produced' by writing a noun, followed by a copula plus an adjective. ${ }^{9}$

To be better able to refer to the two topics just summarised, I suggest the following characterisations:

Novelty Competent language users are typically able to understand sentences that they have never read or heard before, given (i) that they are familiar with the words and syntactic structures occurring in a given sentence, (ii) that the length and complexity of the sentence does not exceed the subject's cognitive resources.

Compositionality Complex natural language sentences seem to be semantically compositional in that the meaning of the whole complex is exhaustively determined by the meanings of the atomic parts the complex consists of ('lexical meaning') and the way in which these parts form a complex ('syntax'), provided the resulting complex is well-formed.

Both issues are closely related, of course. Let me elaborate in some more detail how. The overall picture seems to be this: Novelty is a fact, compositionality is not. The former is usually explained in terms of the latter. Therefore, by construing an account of compositionality, you already indirectly provide an explanation for the Novelty problem. Two further things need to be noted that are implied by what I have said thus far. Firstly, there are different possible explanations, or, to be more precise, there are at least as many explanations for Novelty as for compositionality. And, secondly, if something else explains Novelty, then there is no apparent need to account for compositionality, since compositionality itself is no apparent fact at all (at least not in virtue of the arguments put forth in favour of Novelty).

Why is Novelty a fact and compositionality not? I take it that it is pretty obvious that competent speakers understand novel sentences. ${ }^{10}$ Concerning compositionality, things are a bit more complicated. At least it seems

9 The underlying idea of setting up the procedure this way is probably that, eventually, we may end up with a (possibly hierarchically ordered) inventory of sentence structures that all uniquely determine sentence meaning, given the meanings of their atoms.

${ }^{10}$ If the 'Boris Johnson' example does not move you, think of any other grammatically well-formed English sentence and test it on your departmental colleagues. 
that English sentences are compositional. Especially if-as was common practice in early modern philosophy of language-one focuses on simply structured declarative sentences. Certainly, you might think, the fact that "Socrates is white" means what it does depends, inter alia, on the further fact that "Socrates" stands for Socrates; that "white" denotes a certain colour; and that the syntactic structure of copula sentences somehow ensures that the whole expression ascribes the property denoted by the predicative to the subject of the sentence (or something reasonably similar). This seems natural and is quite plausible indeed. Philosophically speaking, however, the crucial point here is this: whether natural languages such as English really are compositional in the sense just sketched is an empirical question. Compositionality does not follow from the fact that Novelty holds. ${ }^{11}$ The status of Novelty, on the other hand, is not similarly challengeable. For it describes only a phenomenon, not an explanation. Novelty refers to people's alleged ability to understand. Of course, one could imagine a scenario in which the observable phenomena are alike but in which no understanding occurs, as we conceive of it. Still, this does not undermine my present claim, since the relevant understanding referred to in the description is itself part of the phenomenon. For example, people respond to questions by giving certain kinds of answers; they execute certain types of actions in response to commands; they infer specific conclusions from sets of premises; and so forth. This is what we-other speakers of the language community-are able to observe and what we combine with our prior knowledge of semantics and syntax. Therefore, the status of Novelty can't be challenged analogously to compositionality, for it is only about what is observable independently of the theories anyway.

A variety of relevant examples that question the status of compositionality have been discussed in the current literature. The following two are quite illustrative in this respect. Assume that the 'semantic content' of "white wine" is composed of the semantic values of, respectively, "white" and "wine" (just as the semantic value of "snow is white" is composed of the semantic values of its constituents). Then there is a specific 'part' of the

\footnotetext{
${ }^{11}$ Note that here and in what follows I do not presuppose that natural languages are not compositional. My argument specifically attacks the alleged justificatory relation from Novelty to compositionality (and nothing else).
} 
semantic value of the complex expression-i.e. that it means, say, 'white wine'-that stems from the meaning of "white". The relevant part, obviously, seems to be the alleged fact that "white" means 'white' (irrespective of how this gets spelled out in specific theories). Now compare this with the complex expression "white wall". ${ }^{12}$ Apparently, although the expression is complex (and, in fact, looks as if its semantic content were composed of the semantic content of, respectively, "white" and "wall"), the contribution, so to say, that "white" makes to the first complex seems to be different from the contribution it makes to the second one. From this, many authors derive the conclusion that the lexical semantics of, say, "white" must be such that it suits both complexes.

An even more impressive example is the genitive construction. To wit:

To understand what is said by 'He has bought John's book', one must identify the referent of 'he', of 'John' and (perhaps) of 'John's book'. But one must also identify the relation that is supposed to hold between John and the book. [...] 'John's book [...] means something like 'the book that bears relation $\mathrm{x}$ to John'. To understand what is said by means of a sentence in which 'John's book' occurs, this meaning must be contextually enriched by instantiating the variable ' $x$ '. (Recanati 1989, 297298)

The basic idea here is that the semantic content that the genitive construction contributes to the overall content of a noun phrase is seriously underdetermined. Philosophers of language with a refentialist bent are forced to adopt the view that the genitive construction $\left\ulcorner x^{\prime} s y\right\urcorner$ conveys only the 'information' that $x$ stands in some contextually specifiable relation to $y$. But then the further problem is that this does not specify a specific truthevaluable content, if the context that could serve to disambiguate between different relations is left out. The context must be left out, since a context that were 'rich' enough so as to specify a particular relation would entail features that are explicitly forbidden in neo-Davidsonian accounts such

${ }^{12}$ By the way, note that nothing hinges on whether we examine noun phrases, whole sentences, or, indeed, any other type of complex expression. We could just as easily run the example with "That is white wine" and "That is a white wall". 
as common ground, intention-reading abilities, world knowledge, and so forth. However, truth-evaluability is the most relevant threshold in truthconditional accounts (e.g. Borg 2004b, 33, note 25). From a formal semanticist's perspective, then, the problem is that one is forced to admit that the genitive construction contributes specific content to the overall sentential content, but in order to determine which content one would need to refer to contextual features beyond those typically considered (e.g. intentionreading abilities). To put it differently, the crucial aspect of the genitive construction is not its underspecification per se but rather the fact that no truth-evaluable content seems to be retrievable solely on the basis of the sentence. To achieve truth-evaluability, one would need to know which relation is actually claimed to hold between $x$ and $y$, which obviously requires ascriptions of speaker intentions in many cases.

I only cite these examples here in order to illustrate that, in the linguistic and philosophical literature alike, the exact status of compositionality is controversial. In particular, it is controversial whether all areas of natural languages are semantically compositional, or whether some arease.g. 'peripheral' phenomena like sayings-are non-compositional after all. I do not argue for either side. My point is that Novelty is the problem one needs to account for. And with respect to this problem, the argumentative step from here to compositionality is only valid under the assumption that there could be no alternative explanation. ${ }^{13}$ The cited examples can be interpreted as undermining the plausibility of this assumption. Both the semantics of compound expression such as "white wine" versus "white wall" as well as the semantics of the genitive construction, for example, suggest that compositionality is at least not as straightforward as many people think it is. There are examples that are supposed to show that languages are non-compositional in certain respects (e.g. idiomatic expressions such as "jemandem auf die Finger schauen"; Ziem \& Staffeldt (2011)). In con-

${ }^{13}$ Davidson $(1967,23)$ is quite explicit about this; i.e. for him, no such alternative seems possible:

[A] theory of meaning for a language $L$ shows 'how the meanings of sentences depend upon the meanings of words' if it contains a (recursive) definition of truth-in-L. And, so far at least, we have no other idea how to turn the trick. 
trast, the examples I just cited here do not undermine the claim that natural languages are (entirely) compositional. Nevertheless, they show that the lexical meaning must sometimes be specified in such a minimal way thatirrespective of 'actual' pragmatic processes (e.g. Gricean inferences)-the (truth-evaluable) meaning of a sentence can only be determined relative to full conversational contexts.

The issues surrounding compositionality indirectly affect a related issue that I have already touched upon in chapter 2: primary meaning. A compositional language requires stable, lexical meanings of its atomic elements. ${ }^{14}$ Otherwise the semantic content of its well-formed complex expressions (e.g. sentences) can't be determined on the basis of their atomic constituents. In other words, primary meanings, attached to words, are the starting point for semantically compositional complexes like sentences. As I see things, there are basically two solutions here. One is to completely abandon compositionality. ${ }^{15}$ The other option is to preserve a (redefined) notion of "primary meaning" that is capable of accounting for compositionality, but which at the same time does not presuppose a neo-Davidsonian conception in terms of reference relations à la Kirk, Ludwig, Lepore, etc. I will come back to this below.

\subsubsection{Truth-Conditional Semantics}

When it comes to truth-conditional semantics, two names are particularly relevant. The first is Donald Davidson, who 'invented' and popularised truth-conditional semantics in the second half of the last century. ${ }^{16}$ The other highly important figure in this context is Alfred Tarski. His work is the basis for a great deal of Davidson's own work, especially Tarski's highly influential articles The Semantic Conception of Truth (1944) and Der Wahrheitsbegriff in den formalisierten Sprachen (1935). For sake of simplicity, I mainly use the term "truth-conditional semantics" in this chapter

\footnotetext{
14 '[T] he interpretation [of sentences] in terms of truth values requires the existence of tight boundaries [...] between literal and non-literal meaning' (Kayser 2003, 1262).

${ }^{15}$ Which seems highly implausible, as most areas of language do seem to be compositional. This even holds for problematic aspects such as underdetermination that I have just mentioned.

${ }^{16}$ See the references in note 4 , page 129.
} 
when referring to the theory sketched in Truth and Meaning. Other terms used in the literature include "truth-functional semantics", "truth-theoretic semantics", "referential semantics", or simply "(neo-)Davidsonian semantics". ${ }^{17}$

Being a logician and mathematician, Tarski was interested in defining the notion of 'truth' for formal languages, and in particular in developing adequacy constraints for such projects, most notably Convention $\mathrm{T}$ (see below). Although his way of defining "truth" is often referred to as a 'theory of truth', his aims differed from the typical aims of current truth theories (clarifying the nature of truth; exhaustively describing the term "true" in natural languages; accounting for truth with respect to related notions like realism, scientific success, etc.; justifying the choice of particular primary bearers of truth; and so on). From the perspective of today's theories of truth, Tarski's theory is concerned only with a tiny area of what modern theories are dealing with. For example, Tarski was not primarily concerned with the layman's use of "truth", nor did he try to explain why natural languages tend to develop a truth predicate in the first place (questions that are paradigmatic examples of what one would typically expect these days from a theory of truth). ${ }^{18}$ Be that as it may, Tarski's 'truth theory' was highly influential and is influential still. Most importantly, Tarski’s theory

17 "Davidsonian semantics" is self-explanatory. "Truth-conditional" emphasises that neoDavidsonian approaches to semantics aim at (i) showing that stating the truth conditions of a sentence is a way of stating its meaning and (ii) demonstrating how sentential semantic content (truth condition) systematically depends on atomic semantic content (reference relation). "Truth-functional" might be a bit misleading here, since, strictly speaking, only connectives can be truth-functional: the truth value of a sentence containing a connective is a function of the truth values of the sentences connected. "Truth-theoretic" and "referential", in contrast, do not invoke this connotation.

${ }^{18}$ Tarski explicitly denies that his theory aims at being in accordance with natural languages:

[...] the very possibility of a consistent use of the expression "true sentence" which is in harmony with the laws of logic and the spirit of everyday language seems to be very questionable, and consequently the same doubt attaches to the possibility of constructing a correct definition of this expression. (Tarski 1935, 279, quoted according to the translation by J. H. Woodger (1983) in J. Corcoran, ed.,'Logic, Semantics, Metamathematics', Hackett, Indianapolis, p. 165.) 
lay the ground for Davidson's work, which is based on the assumption that a Tarski-style theory of truth can be 'converted' into a theory of meaning (Kölbel 2001, Newen \& Schrenk 2008).

Central to Tarski's work is the so-called Convention T, which is the requirement that the theorems of one's truth theory should take the form of instances of the following schema: ${ }^{19}$

(T) “ $p$ ” is true iff $p$.

Let me first very briefly explain how it works. First of all, with (T) comes the distinction between object language and metalanguage. Let German be the object language, i.e. the language we talk about in the following statements. Then a simple instance of $(\mathrm{T})$ is

$\left(\mathrm{T}_{1}\right)$ "Schnee ist weiß" is true iff snow is white.

The corresponding metalanguage, then, is the language one uses to talk about sentences of the object language (here: English sentences that deal with the truth conditions of German sentences). Notably, $\left(\mathrm{T}_{1}\right)$ as a whole is written in our metalanguage, English. The expression

"Schnee ist weiß"20

is part of English, it is a name $e^{21}$ for the German sentence "Schnee ist weiß". Much confusion in regard to the schema stems from many authors' tendency to use English both as their metalanguage and object language. Things are far easier to explain if one chooses different (natural) languages for the respective purposes. Especially since we actually use a meta-metalanguage when we describe the relationship between the 'lower' two languages.

I said that

"Schnee ist weiß"

\footnotetext{
${ }^{19}$ The schema is called 'T-schema', its instances are 'T-sentences'.

${ }^{20}$ Note my use of meta-metalanguage here.

${ }^{21}$ I emphasise "name" here, because competent speakers of a natural language (in particular, speakers who master German) often times can't help themselves seeing a structure here. But this is misleading. The quoted expression is technically just a name, i.e. a non-decomposable semantic atom.
} 
i.e. the result of writing double quotation marks, followed by the sentence "Schnee ist weiß", and again followed by double quotation marks is a name (in the metalanguage) for the German sentence that says that snow is white. There are other ways of referring to object-level sentences. Using quotation marks and the 'original' sentence of the object language is the most convenient and usual one, however. ${ }^{22}$ Another option would be to say that the German sentence built by writing the sequence of letters (and spaces) "S", "c", " $h$ ", ..., "e", "i", and " $\beta$ " is true in German iff snow is white. That is to say, one could employ a structural description of the sentence at hand (in terms of German letters). This is the method originally suggested by Tarski. All this, in any case, is part of the metalanguage. The underlying idea that everything expressible at the object-level must also be expressible at the meta-level is often expressed by saying that the metalanguage must 'contain' the object language. ${ }^{23}$ Using two different natural languages when describing what is going on helps understanding the difficulties.

An example will illustrate this. Suppose now that I use English both at the object-level and at the meta-level. The probably most often quoted instance of the T-schema then reads:

$\left(\mathrm{T}_{2}\right)$ "Snow is white" is true iff snow is white.

This is misleading, because there is actually no structural similarity between the right-hand side and left-hand side of this instance. This was somehow transparent in $\mathrm{T}_{1}$, but in $\mathrm{T}_{2}$ it seems that "Snow is white" occurs two times actually. This is not the case, since the expression on the lefthand side of the copula is an unstructured entity, a name for an object-level expression. So, since instances of "Snow is white" at both levels express the proposition < snow is white $>$ (as they do by assumption), the meta-level sentence must be a step-by-step translation of the object-level sentence. This is what Putnam means when he says that when we determine Eng-

${ }^{22}$ It is clear what I mean here; yet, strictly speaking, it is not the original German sentence that I use here, for the whole expression in question is in the present metalanguage.

${ }^{23}$ A bit more precisely formulated: (i) it must contain the relevant part, i.e. translations of the sentences one wants to insert into the schema; (ii) it must contain names of the relevant object-level sentences (or otherwise a method of referring to these sentences, e.g. structural descriptions); (iii) it must contain a certain amount of logic, "iff" in particular. In sum, it must be 'semantically richer'. 
lish to serve a double-purpose as both metalanguage and object language we '[decide implicitly] that each sentence of [object-level English] is to be translated "homophonically" into [metalevel English]' $(1985,69)$.

It is in the same paper that Putnam claims that Tarski's theory fails to be an account of our colloquial "true" (as if that were Tarski's intention):

Now, pay close attention, please! This is just where, it seems to me, philosophers have been asleep at the opera for a long time! Since (2) [(for any sentence X) If X is spelled S-N-O-WSPACE-I-S-SPACE-W-H-I-T-E, then X is true in L if and only if snow is white] is a theorem of logic in meta- $\mathrm{L}$ (if we accept the definition-given by Tarski-of "true-in-L"), since no axioms are needed for the proof of (2) except axioms of logic and axioms about spelling, (2) holds in all possible worlds. In particular, since no assumptions about the use of the expressions of $\mathrm{L}$ are used in the proof of (2), (2) holds true in worlds in which the sentence "Snow is white" does not mean that snow is white. In fact, "true-in-L," as defined by Tarski, is a notion which involves only the primitive notions of $\mathrm{L}$ itself $[\ldots]$. So if $\mathrm{L}$ does not have notions which refer to the use of linguistic expressions, there is no way in which "true-in-L," or, rather, the notion to which Tarski gives that name, could involve the use of expressions in any way. The property to which Tarski gives the name "true-in-L" is a property that the sentence "Snow is white" has in every possible world in which snow is white, including worlds in which what it means is that snow is green. (Putnam 1985, 63-64)

The controversial bit is the very last claim; that a sentence like $\mathrm{T}_{2}$ is a theorem of Tarski's theory in all worlds. That would be disastrous for the theory, even if it is not designed to capture ordinary uses of the truth predicate. I will now show that Putnam is mistaken here.

Suppose you open any good textbook on astronomy. In the introductory paragraphs you read this:

A position on the Earth is usually given by two spherical coordinates. $^{24}$

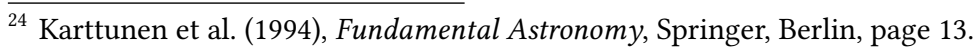


Now, if this sentence meant that 'Hansel and Gretel went into the forest to fetch some wood', then the book you would be looking at would contain rather a fairy tale than basic astronomical knowledge. In order to ensure a 'standard' interpretation of his remarks, the author of this book needs to do nothing. The same goes for books on truth. The whole description of the theory (including the description of meta- $\mathrm{L}$ and how to derive theorems in meta-L) is given in a meta-metalanguage, which is English in this case. In this language, "white" denotes whiteness, "snow" denotes snow, and so forth. This is precisely the interpretation that is in accordance with how we, writers and readers of English, use these terms. Like the astronomer, Tarski does not need, therefore, enforce this interpretation explicitly. So when we read (in meta-meta-English) that the object-level expression "snow" refers to snow (cf. the 'base clauses' in Glanzberg 2013), this is enough to make sure that "snow" at the object level is used to refer to snow. When Putnam talks about "worlds in which what "Snow is white" means is that snow is green', the most straightforward answer to the problem he posits is this: if the only thing that deviates from the actual world is that "white" refers to the colour green, then in the metalanguage for this version of English

"Snow is white" is true iff snow is white would no longer be a theorem of the truth theory, since the axiom "white" refers to the colour white would be 'replaced' in that theory by the axiom

"white" refers to the colour green and, hence,

"Snow is white" is true iff snow is green would turn out true in that modified theory. ${ }^{25}$ Which, by any standards, is an unproblematic theorem relative to the assumptions mentioned above.

${ }^{25}$ Cf. Patterson $(2012,136)$ :

If the intuitive meaning of an expression of the object language changes, Tarski's definition needs to be reworked to capture the concept of truth for the language so re-interpreted. This is a consequence of the fact that intuitive meaning is an "off table" matter to be kept in mind of the users of the theory $[\ldots]$. 
Note that something like the substitute axiom must come into play somewhere, for this is how the deviant variant of English is defined by Putnam in the first place. He notes that in this specific world he is talking about 'it [the snow sentence] means that snow is green', which is one way of expressing the idea that specific axioms hold for the semantics of that word (e.g. "“white' refers to the colour green"). Considering other worldsworlds in which words function differently-is to allow for a different set of T-sentences.

Another important thing to note in regard to $(\mathrm{T})$ is that there are at least a handful of varieties of how to state the schema. ${ }^{26}$ Different 'stylistic' variants of the schema are for the most part motivated by technical niceties, most of which do not concern me here. The most important technical problem is this: in (T), I applied regular quotation marks; so, strictly speaking, I quoted " $p$ ". But " $p$ " is a sentence variable, to be substituted by a declarative sentence of the object language. This occurrence then gets quoted. When I moved from the schema to a particular instance-i.e. from

$$
\text { " } p \text { " is true iff } p
$$

to

"Schnee ist weiß" is true iff snow is white

-I immediately applied the 'intended' reading of the schema. Some theorists circumvent this problem by using quasi-quotation; others use-like Tarski-structural descriptions to denote sentences. Having said this, I shall use the simple notation in what follows.

Last comment on (T): Tarski's method introduces a hierarchy of truth predicates. Truth, that is, may only be attributed to sentences at a lower semantic level. This gives me a further reason to not use English both as metalevel and object-level language (even if only for pedagogical reasons). Suppose I did. Then the question Does English have a truth predicate? would become ambiguous. Yes, it does, if used as a metalanguage. But as an object language it does not, at least not the one needed to attribute truth to its own sentences. ${ }^{27}$ This is obscured by sentences like

${ }^{26}$ Cf., e.g., Priest's (2006, 17).

27 The reason that in a Tarskian framework "true" is not applicable to sentences that belong to the same (level of) language as "true" itself belongs is that this would lead us to para- 
"Snow is white" is true iff snow is white

because such examples suggest that we may say in English that the English sentence "Snow is white" is true, but we can't if we accept the Tarskian idea of hierarchically ordered languages. Whether this idea itself is plausible is irrelevant for the present considerations. I am only interested in truth to the extent that it affects theories of meaning. In this section, in particular, I am only interested in truth to the extent that it affects Davidson's and neo-Davidsonians' theory of meaning. If only to avoid unnecessary confusion, it is worth employing at least two natural languages; one as object language, and a different one as metalanguage (and meta-metalanguage).

Back, then, to where I began. I gave only a very brief overview of Tarski's work. ${ }^{28}$ What is most important in the present context is that Tarski takes certain semantic notions for granted: "refers" and "satisfies". One might say that he presupposed a theory of meaning (as reference and satisfaction can only be defined in terms of meaning), and built a 'theory of truth' on it (i.e. he kind of reversed the Davidsonian programme). For example, we read that

In view of the situation [i.e. in view of the need for a recursive definition of "truth"], there is no method with which it would be possible to recursively define the investigated notion. On the other hand, it is possible to introduce a general concept that is applied to arbitrarily many propositional functions, that is recursively definable, and that leads us immediately to truth, if applied to propositions ['Aussagen']. It is the notion of satisfaction of a given propositional function by given entities-in the case at hand, satisfaction by classes of individuals-that meets these requirements. (Tarski 1935, 307) ${ }^{29}$

doxes, most prominently the liar paradox. For a possible solution of how to reconcile a hierarchical solution to the liar paradox with the intuition that natural languages have (each) just one truth predicate, see Horwich (2010, 87-91).

${ }^{28}$ For a closer look, see Patterson (2012).

${ }^{29}$ My translation (of the German version), spacing omitted. The original publication in 1933 was in Polish. The German translation reads:

Angesichts dieser Sachlage lässt sich keine Methode angeben, welche es erlauben würde, den untersuchten Begriff unmittelbar auf rekursivem Wege 
Tarski's groundbreaking idea is to omit a full-blown definition of "truth". He circumvented the problem of providing such a definition by saying, roughly, that all $\mathrm{T}$-sentences of a given language that comply with Convention T are partial definitions of the concept of truth. Patterson (2012) summarises Tarski's strategy as follows:

[...] what we find is that an expression for which the T-sentences are theorems is, given the conventions governing the object language and the metalanguage, forced to express the content of the concept of truth as construed in the semantical definition [for all $\mathrm{x}, \mathrm{x}$ is a true sentence if and only if, for a certain $p, x$ is identical with 'p' and $p$ ]. Since the language of the metatheory has intuitive meaning just as much as does the object language $[\ldots]$, each T-sentence is meaningful $[\ldots]$ in accordance with linguistic usage. In particular, a T-sentence like:

["snow is white" is true iff snow is white means that "snow is white" is true iff snow is white $]^{30}$. Now, though the T-sentence itself says nothing of its own saying that something is the case, a party to the conventions governing the metalanguage will recognize that in fact the T-sentence does say $[\ldots]$ exactly that. (119)

Mutatis mutandis, the same holds for 'a party to the convention governing the object language'. Thus, the basic idea that Tarski put forward is that someone who masters both object language and metalanguage will accept T-sentences in such a way that the applicability of "true" corres-

zu definieren. Es ergibt sich aber die Möglichkeit, einen Begriff von allgemeinerem Charakter einzuführen, welcher bei beliebigen Aussagefunktionen Anwendung findet, sich schon rekursiv definieren lässt und, auf Aussagen angewendet, uns mittelbar zum Begriff der Wahrheit führt; diesen Bedingungen genügt nämlich der Begriff des Erfülltseins der gegebenen Aussagefunktion durch gegebene Gegenstände und im vorliegenden Falle - durch gegebene Klassen von Individuen.

${ }^{30}$ I substituted the example sentence in order to simplify at this point. 
ponds perfectly to our pre-theoretic understanding of the truth predicate (Patterson 2012, 117-122).

Davidson now reverses this order, or so many interpret him. For him, truth is a self-evident, transparent concept (Newen \& Schrenk 2008). In other words, one does not need, says Davidson, other concepts (in the relevant sense) to understand the meaning of "true". One is asked to take its meaning for granted and base a theory of meaning on it. A very clear way of saying where we are getting at here is to say that Davidson's claim is that a Tarski-style theory of truth is a theory of meaning (cf. Lepore 2006). My task in the following paragraphs is to explain what this methodological dogma amounts to.

Tarski told us how to build a theory of truth for specific formalised languages (and how to test its adequacy). Its axioms determine the extensions of all 'atomic parts' of this component of English. Thus, in regard to names, for example, we might have a list that relates them to individual objects; we might have another list that relates predicates to $n$-tuples of individuals; and we have recursively formulated rules that determine the extensions of all well-formed sentences as functions of extensions of the atomic parts of the sentence in question. Here is an example to illustrate this: if "Aristotle" refers to Aristotle (which is settled in an axiom list for names) and " $x$ is a human" is satisfied iff the substitution instance of " $x$ " refers to an entity that belongs to the class of humans (again, set by an axiomatic list for predicates), then the sentence "Aristotle is a human" is true iff Aristotle is a human (i.e. actually true, if the formal theory is accurate).

Here is how Glanzberg (2013) summarises Tarski's approach somewhat more generally:

Tarski notes that truth for each atomic sentence can be defined in terms of two closely related notions: reference and satisfaction. Let us consider a language $\mathbf{L}^{\prime}$, just like $\mathbf{L}$ [i.e. a language containing two specific well-formed sentences] except that instead of simply having two atomic sentences, $\mathbf{L}^{\prime}$ breaks atomic sentences into terms and predicates. $\mathbf{L}^{\prime}$ contains terms 'snow' and 'grass' (let us engage in the idealization that these are simply singular terms), and predicates 'is white' and 'is 
green'. So $\mathbf{L}$ ' is like $\mathbf{L}$, but also contains the sentences 'Snow is green' and 'Grass is white'.

We can define truth for atomic sentences of $\mathbf{L}^{\prime}$ in the following way.

1. Base clauses:

1. 'Snow' refers to snow.

2. 'Grass' refers to grass.

3. $a$ satisfies 'is white' if and only if $a$ is white.

4. $a$ satisfies 'is green' if and only if $a$ is green.

2. For any atomic sentence $\ulcorner t$ is $P\urcorner:\ulcorner t$ is $P\urcorner$ is true if and only if the referent of $\ulcorner t\urcorner$ satisfies $\ulcorner P\urcorner$. (Emphasis omitted)

We see here that it is possible to construe a Tarski-style truth theory for a small, formalised fragment of English, i.e. a theory that produces, for all well-formed sentences of that fragment of English, T-sentences that specify truth conditions for these sentences. 'Davidson is known for having reinterpreted Tarski's theory of truth as a theory of meaning, and for applying it to ordinary language' (Newen \& Schrenk 2008, 56, my translation). Instead of taking semantic notions for granted (e.g. "satisfies") and 'explaining' truth in terms of these notions, Davidson did just the opposite by taking 'truth' for granted in order to explain meaning. The idea here is that the body of knowledge that we theoreticians need to postulate when trying to account for competent language users' comprehension abilities must resemble the structure of a Tarski-style 'truth theory'.

\subsection{Truth-Conditional Semantics at Work}

In the previous section, I presented the main ingredients of truth-conditional semantics by showing two things. Firstly, in preparation of this section and the discussion in the next chapter I said a few words about one major argument employed by Davidson (the argument from sentence comprehension). Then, secondly, I discussed the-admittedly, highly simplifiedDavidsonian programme of transforming a Tarski-style 'theory of truth' 
into a theory of meaning. Accordingly, the aim of the present section is to apply this framework to the initial problem (sentence comprehension). Again, I would like to show two things here. On the one hand, TCS seem particularly likely to be a possible solution to the cited 'problem', i.e. people's capability to comprehend any well-formed sentence of their respective languages. Showing why this seems to be the case is one of my aims. On the other hand, there are good reasons to suppose that Davidson's central claim-which is that his proposal is in effect the only possible solution to the problem-is false. That is to say, there are viable alternatives. Moreover, for reasons emerging throughout the book (especially in the methodological part), the alternatives are the preferred options. Let me now first turn to the pros of truth-conditional semantics.

\subsubsection{Linking Novelty and Compositionality}

A closer look at why compositionality and Novelty are discussed together in one chapter and why truth-conditional semantics seems adequate to account for both will help us to see the major advantages of this approach. These advantages set the threshold for potential alternatives. According to TCS, a theory that produces infinitely many sentences of the form " ' $p$ ' is true iff $p$ " can be regarded a theory of meaning. ${ }^{31}$ Davidson says that what an adequate natural language semantics should be able to do is stating truth conditions for all well-formed sentences of the relevant target language. ${ }^{32}$ It can be considered controversial whether truth conditions represent all there is to know about the meaning of a sentence. The classical passage on this issue reads as if Davidson thought this were the case:

There is no need to suppress, of course, the obvious connection between a definition of truth of the kind Tarski has shown how to construct, and the concept of meaning. It is this: the

${ }^{31}$ Save for some exegetical niceties that I waive here: e.g. Davidson's contention that truth conditions and meaning are not the same, but that 'giving the truth conditions of a sentence' is one way of stating its meaning.

32 See Davidson (1967, 34-35) for some remarks on demonstratives and, accordingly, on what roles utterances might play in his account. Even if we would take into account sentences relativized to formally specifiable contexts of utterance, we would still leave out most semantically relevant aspects of utterances that I mentioned above. 
definition works by giving necessary and sufficient conditions for the truth of every sentence, and to give truth conditions is a way of giving the meaning of a sentence. (Davidson 1967, 310, emphasis added) $)^{33}$

The following, I think, is uncontroversial: firstly, it is true that a theory of meaning should at least be compatible with Convention $\mathrm{T}$, or more specifically, with the view that every sentence somehow 'indicates' its own truth conditions ('sentences bear their truth conditions on their sleeves', as it is often put). Secondly, truth conditions are important aspects of meaning that are relevant in many areas of theorising. Thirdly, everyone who understands a particular T-sentence knows something, albeit very little, about the meaning of that sentence. ${ }^{34}$ I deny, however, that it is a necessary condition for an adequate theory of meaning that it entails all, or indeed any, relevant T-sentences.

Moreover, it can be doubted that truth conditions are all there is to know about the meaning of sentences. To argue for this is to say something about when one is usually satisfied with an answer to the questions of the type "What does sentence $x$ mean?" Suppose you learn that "Snow is white" is true iff snow is white. Essentially, two possibilities are available here: either you knew in advance what "snow", "is", "white", and the syntactic structure 'S-C-P' ( $\mathrm{S}=$ subject; $\mathrm{C}=$ copula; $\mathrm{P}=$ predicative) mean, or you did not. In the first case, you did not 'learn' anything because you already knew

33 The widespread conviction that Davidson identifies meaning with truth conditions probably stems from this passage. It seems natural to interpret this paragraph accordingly (cf., e.g., Saka 2007).

${ }^{34}$ This holds with certain provisos: (a) Here I assume the Horwichian understanding of "understanding", namely that "understanding" means, roughly, 'to know how to use'; (b) furthermore, I presuppose that T-sentences are wholly formulated in a metalanguage, i.e.

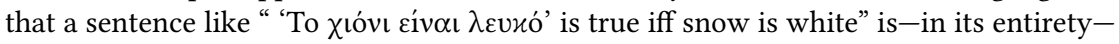
an English sentence; (c) I assume further that, e.g., one who merely understands this

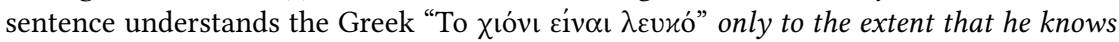
that in Greek this sentence corresponds to the English "Snow is white" (and, hence, has such-and-such truth conditions), which is to say that he does not know, from that bit of

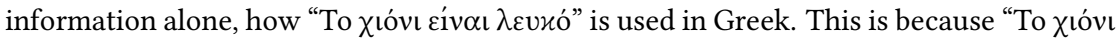
civ $\alpha \mathrm{L} \lambda \varepsilon \cup \varkappa o$ " plus quotation marks is an English name, and because of this everyone who masters English and is familiar with the T-schema does not need any further competence in order to understand the 'Greek T-sentence'. 
the truth conditions of "snow is white" anyway (hence, asking would be superfluous). In the second case, you do not learn anything either because you are unable to understand the proposed explanation.

The natural reply by truth-conditional semanticists is to say: "Actually, I never claimed that T-sentences are in any way "interesting" or that you learn anything about meaning with the help of my theory. I only say that my theory provides meanings for all sentences-and this is what we expect of such a theory.' Not quite. If T-sentences were all we could come to know about sentence meanings, then the fact that "What does $x$ mean?" is a common question and normally demands an illuminating answer would be inexplicable. For it is far too trivial for many grammatical sentences in natural languages to work out their respective truth conditions. No one would ever think of asking such questions if the only answers solely consisted in truth-condition statements.

To be sure, this little argument is far from being conclusive. Neither Davidson nor his followers are particularly concerned with the role of meaning inquiries in layman's usage. Still, the notion of 'meaning' that Davidson is after can't be conceived completely independently of the folk notion it originates from, for this would render his whole argumentation implausible. Remember that the key step in Truth and Meaning is the presumption that "is true" is an extensionally correct substitute for the allegedly obscure "means that". ${ }^{35}$ By the same token, it seems justified to require of Davidson's theory that, as far as non-metaphorical use of "meaning" is concerned, it should resemble the folk notion as far as possible. And it is a commonplace that locutions such as "What does $x$ mean?" and their corresponding answers are among the most central applications of the notion of 'meaning'-locutions that seem incompatible with an understanding of meaning based merely on truth conditions.

35 By which I do not want to suggest that Davidson aimed at replacing meaning by truth conditions. I am only referring to the well-known, often-cited passage in which he says:

As a final bold step, let us try treating the position occupied by 'p' extensionally: to implement this, sweep away the obscure 'means that', provide the sentence that replaces ' $p$ ' with a proper sentential connective, and supply the description that replaces' with its own predicate. The plausible result is

(T) $s$ is $T$ if and only if $p$. (Davidson 1967, 23, emphasis added) 
What, then, is the alternative? In an abstract sense, the answer is simple: one is typically satisfied with a 'meaning statement' if the corresponding answer illuminates one's understanding of the sentence in question, or, otherwise, if it conforms with what one knows about the sentence's meaning anyway. This amounts to saying that we tend to be satisfied with answers to meaning inquiries whenever they help us to see how the sentence in question is (typically) used.

Here are a few examples. First example: if you do not know German, then the (English) explanation "'Schnee ist weiß' is true iff snow is white" (read: "Schnee ist weiß" means 'Snow is white') helps you to understand (i.e. indicates how to use) "Schnee ist weiß" to the extent that you would fully understand it once you understood related sentences. ${ }^{36}$ Second example: if two people are in front of a library and one of them says "This is Tom's bicycle" and I say to you, describing this situation, that this means that the guy wants the girl to know that her ex-boyfriend is in the library, then you probably understand this sentence (ceteris paribus). That is to say, you would come to know that it is used to say something about the whereabouts of Tom, albeit that the sentence is 'about' a bicycle and its literal truth conditions do not depend on Tom. ${ }^{37}$ Last example: if you are an

\footnotetext{
${ }^{36}$ This last proviso is essential. Only when you know the use of all related sentences of "Schnee ist weiß", then you fully understand the sentence itself. If you learn only this individual fact-that "Schnee ist weiß" means 'Snow is white'-then your knowledge of the use of "Schnee ist weiß" is, so to speak, potential knowledge. That is, you do not really associate a particular use with this sentence, because you are unable to connect this bit of information with other relevant knowledge. In the case of "Schnee ist weiß", the immediately 'related' sentences might be "Das ist Schnee" and "Das ist weiß", for example (cf. also Davidson 1967, 26, note 10).

37 This is essentially Tomasello's example (from his 2008, page 3 ). The point of this example is that it illustrates (for arguments, see below) that the context that determines content is often times very wide. In this particular case, for instance, this content would have been different two weeks earlier, or with another interlocutor, and so on. Generally, the content would have been different with different shared background knowledge. In Tomasello's own words:
}

It is easy to say that what carries the meaning in these different examples [i.e. variations of the one above] is "context," but that is not very helpful since all of the physical features of the immediate communicative context were (by stipulation) identical in the various scenarios. The only difference was our shared experience beforehand [...]. (2008, 3-4) 
otherwise competent speaker of English but do not know the word "apple", and you're told that "apple" means 'a round fruit with firm juicy flesh', ${ }^{38}$ then you understand will "apple" (or sentences containing "apple', for that matter), because you know how it is used in sentences whose other constituents you are already familiar with, like "This is an apple", "Apple is good for making cakes", "I like apples" and so forth.

One possible reply is to point out that this way of arguing mixes up the distinction between semantics and pragmatics, and that, in particular, too much pragmatics enters into the presented examples. The argument here would be along the lines of: the central locutions in which "means" occurs is when semantics is at stake; which is clearly not the case in, for example, Tomasellian common-ground scenarios. But this is grist to my mill, for as I argued already in section 2.2, this distinction is blurred (at least) in recent empirical work in construction grammar. Moreover, to say that semantics covers only truth conditions is clearly an exaggeration, for many much more 'conservative' approaches comprise (quasi-)pragmatic aspects as well. See, for example, Recanati's contextualism (e.g. Recanati 2007).

A further objection might be this: the semantic approach that is suggested by the above examples implies that one can't know the meaning of a term or sentence tout court but that understanding essentially comes in degrees. True, but this is actually a virtue of my view. Here, again, I can offer no waterproof armchair argument; I only say that this is the most plausible way to make sense of our de facto 'meaning discourse'. It is perfectly reasonable to say things like "She has only a vague idea of what we are talking about"; "More and more he understood what they said"; "I don't know what it means precisely", etc. If meaning were an all-or-nothing game, this part of our discourse would not be intelligible at all. Also, meaning holism already suggests that people learn word meanings one step at a time. ${ }^{39}$

${ }^{38}$ Hornby, A. S. (1995), Oxford Advanced Learner's Dictionary, Oxford University Press, London, p. 46.

${ }^{39}$ Meaning holism is here understood as the thesis that the meaning of a word depends on the meanings of other words of the same language. There is a vast range of theoretical possibilities when it comes to holism, most of which I will simply neglect at this stage. For a concise overview, the reader is asked to consult Pagin (2006). There are also some illuminating passages in Horwich, or in Fodor, or in Quine. The main idea, though, is 
Competent speakers know the meaning of a term only to the extent that they are familiar with (more or less) related terms. Since one can't learn a whole language at one go, people improve their knowledge as they learn more and more words (or, in general, broaden their linguistic competence). Eventually, natural language speakers' way of dealing with technical terms also shows that knowledge of meaning comes in degrees. Think of a term like "full employment": probably every competent language user of English knows the meaning of this term in the sense that he is able to use it appropriately and knows how others typically will (potentially) use it. Very few of us, however, are familiar with the available exact definitions of "full employment" and that, hence, the term varies in its extension depending on the particular theoretical background applied. So, if an average speaker is not sure as to whether "full employment" applies to a situation where, say, $3 \%$ of a particular population are unemployed, then this uncertainty is neither due to vagueness (all definitions of "full employment" have strict boundaries), nor due to incompetence (he would know that "full employment" means 'that almost all are employed'), but due to his restricted knowledge as regards the relevant meaning. That is to say, he knows the meaning of the term merely to a certain extent, which is to say that his semantic understanding comes in degrees.

\subsubsection{Truth-conditional Semantics Does the Trick}

For the reasons I pointed out in the previous subsection, TCS seems to be particularly well-suited to account both for the Novelty problem as well as for compositionality. The simple reason is that both issues are basically treated as two sides of the same coin: since Novelty can only be explained via referring to compositionality (or so Davidson argues), providing a solution for the latter means solving the former as well. Now I would like so show in some more detail why this seems so. First of all, I assume for

simple and always remains the same: given meaning holism, it is impossible to assign meaning to atomic elements of a given language independently of the meanings that get assigned to related elements of the same language. In this sense, learning a language stepwise and holism always come together: holism implies the epistemic constraint that knowledge of the meaning of a particular term depends on one's potentially restricted knowledge of the meanings of related terms. 
the sake of argument that the following holds: (i) meanings are truth conditions, i.e. there is no semantic information of a given sentence exceeding its propositional content; (ii) truth-conditional semantics 'works', i.e. a broadly neo-Davidsonian approach can be applied to a reasonable sample of natural English.

The compositionality principle requires us to provide a mechanism that computes the meaning of a sentence, given the meanings of its atomic parts and the way they are put together. By assumption, TCS-certainly so in neo-Davidsonian approaches-is a theory that connects words of English with meanings. ${ }^{40}$ Furthermore, a Tarski-style theory of truth tells us in which way the truth conditions of any well-formed sentence depend on the meanings of its parts. Here is a simple example. I begin with meaning statements for atomic units of a given language: ${ }^{41}$

$r_{1}$ "Snow" refers to snow;

$r_{2}$ "Socrates" refers to Socrates;

$f_{1}$ " $x$ is white" is a function that is satisfied if $x$ is white, otherwise false ${ }^{42}$

$c_{1}$ A sentence of the form " $x$ is $F$ " is true iff $x$ satisfies " $x$ is $F$ ".

A brief look at the relevant complex sentence "Snow is white" reveals that one can easily combine the above basic information. The result is

${ }^{40}$ These meanings are referents in the case of names, functions in the case of predicates, and so on. The two above assumptions ensure that all (or a significant portion of all) English words are covered and that the kind of meaning provided captures the full meaning of a term.

${ }^{41}$ The presentation of these 'base clauses' in a Tarski-style framework is adopted from Glanzberg (2013). Again, I do without quasi quotation.

${ }^{42}$ For ease of presentation, I simplify a bit. For example, one would actually need to first state the meaning of "white" and then explicate the meaning of predication (or "be" when used as a full verb). The combination of the two is the meaning of " $x$ is white". 
"Snow is white" is true iff snow is white

which is, relative to the above assumptions, an exhaustive description of the meaning of "Snow is white". In short, it is relatively obvious that it is a direct consequence of my second assumption ('TCS works') that truthconditional semantics can successfully handle compositionality issues.

Things get a bit more complicated when I now turn to Novelty. The problem is that there is a discrepancy between the potential infinity of well-formed (grammatical) sentences of natural languages that language users are basically able to understand and the finitude of cognitive resources that can explain this. To bridge this gap, says Davidson, one needs recursion/recursiveness. Tarski's apparatus that I employed above when demonstrating how the meaning of a sentence depends on its parts essentially involves a recursive strategy. The rules for determining the meaning (truth conditions) of complexes may be applied ad libitum. In particular, the rules may be applied several times in building sentence meanings. This ensures that by using this method, one is able to determine the meaning of declarative sentences of any length.

To account for the fact that language users are typically able to understand sentences they have never encountered before, truth-conditional semanticists assume that a competent speaker (implicitly) knows such recursive rules roughly as described by Tarski. ${ }^{43}$ The meaning of any complex sentence can be built recursively with these rules. By analogy, the same mechanism is supposed to explain language users' ability to comprehend novel sentences. All this is pretty straightforward and well established, so there is no need to go too much into the details. Especially so, since what is really interesting is not the argument as such but rather the plausibility of its main premises. The two premises that, for the sake of argument, I assumed above were these: (i) meanings are truth conditions; (ii) truth-conditional semantics is a successful enterprise. I shall now consider both premises in turn and argue that they are unwarranted.

${ }^{43}$ To be fair, this is, to my knowledge, never stated explicitly. But this is the only way I can think of to make sense of Davidson's claim that his semantic theory provides the only solution to the problem that natural languages must be learnable (Davidson 1965). Note, though, that the status of Davidson's project as aiming at psychological reality is at least debatable (Röska-Hardy 2005). 
Ad (ii): I start with the claim that TCS is successful. To be sure, there are many relevant respects in which theories can be more or less successful. I shall here concentrate on one particular mark of adequacy: a theory should in fact be able to explain all phenomena that it officially says it is applicable to. Semantics is the study of meanings of sentences. ${ }^{44}$ If you like, you may even add the restriction that semantics proper is solely concerned with sentence meanings irrespective of context. This problem can be bracketed out for the moment. Yet, semantics supposedly is the study of all sentences. One crucial deficit of TCS is its initial restriction to a particular class of sentences, namely declaratives. ${ }^{45}$ There are quite a lot of attempts to enlarge the class of sentences covered by classical truth-conditional or broadly formal semantics. This holds in particular for formal treatments of questions. ${ }^{46}$ The central difficulty remains, though, namely that all broadly formalist approaches to the semantics of non-declaratives are attempts to extend a theory designed for declaratives to other forms (not like usagebased theories, which are intended to apply across the board from the very beginning). The simple reason for excluding other types of sentences is that only truth-evaluable sentences can have truth conditions.

It can be considered uncontroversial that declarative sentences is the only class of truth-evaluable sentences, i.e. only sentences belonging to that class can reasonably be assigned truth values. Think of questions, exclamations, emotional expressions, imperatives, and the like. They can hardly be said to have truth-evaluable content, although much ink has been spilt-

${ }^{44}$ This, at least, is probably the most widespread position in philosophy and certainly an undisputed truism in linguistics. As usual, there are people who deny even truisms:

Syntax studies sentences, semantics studies propositions. Pragmatics is the study of linguistic acts and the contexts in which they are performed. (Stalnaker 1970, 275)

According to this characterization of semantics [i.e. semantics as the study of propositions], then, the subject has no essential connection with languages at all, either natural or artificial. (274)

${ }^{45}$ I ignore for the moment that within this restricted class there are probably further areas that are not accounted for satisfactorily in Davidsonian semantics; e.g. underdetermination as exemplified by the genitive construction discussed above.

${ }^{46}$ Belnap (1982), Higginbotham (1996), Krifka (2007, 2012). 
especially in linguistics-on complementing truth conditions with conditions of fulfilment or use conditions. ${ }^{47}$ So, at best, TCS covers a wide range of sentences but is at the very least not directly applicable to many other types of sentences. If this is right, an alternative semantics for the remaining sentences is required. Prima facie, there is no reason to suppose that this alternative would lack the resources to account for declarative sentences, too. To be sure, the status of TCS as a semantic theory of declarative sentences remains unclear as long as there is no reasonable alternative. But if there were such an alternative, the restriction of truth-conditional semantics to a particular class of sentences would speak against the theory.

Otherwise, truth-conditional semanticists might want to argue that they conceive of their theory as a universal semantic theory. It is just that so far no one has fully worked out the details for sentences that involve nontruth-evaluable content. This seems equally problematic, for why should we think that the existing theory sketch would be applicable to questions, imperatives, and the like? In fact, there is ample reason to doubt this. Questions will serve as an example. Similar reasoning could be applied to other types of sentences though. Propositions are the primary bearers of truth and hence determine the corresponding truth conditions for sentences that are used to express them. ${ }^{48}$ In this view, declarative sentences are truthevaluable because they express propositions. Consider the question "Is red

${ }^{47}$ Classically, propositions are considered primary bearers of truth. Declarative sentences are said to express propositions. In this view, declaratives are truth-evaluable derivatively: they directly inherit their truth values / truth conditions from the propositions they are used to express. For example, "snow is white" expresses the proposition <snow is white>. Questions do not express propositions in this sense, hence they lack truth value, which, however, is not to deny that questions do not relate to propositional content. It is just that there is no 1-to-1 correspondence as in the case of declaratives. Hence, the mechanism, if any, that relates propositional content ("that $p$ ") to the semantic content of a question (e.g. "Is it the case that p?") must be something different. Be that as it may, no matter what the exact relation is here, due to conceptual reasons questions as such can't be truth-evaluable. The same holds for commands, etc., which can only be satisfied but can't be true.

${ }^{48}$ At least, I will assume this in what follows. See Horwich (1998, 16-17, 86-90) for a justification. The argument, however, is independent of specific views on truth; it may easily be redescribed in terms of sentences as primary truth bearers. 
Tom's favourite colour?" What would be an appropriate way to associate this question with a proposition?

Irrespective of how we might connect the question with a corresponding proposition and, by doing so, with its alleged 'truth conditions', the obvious candidate for this job is the proposition < red is Tom's favourite colour $>$. But whereas the sentence "Red is Tom's favourite colour" is (as per TCS) true iff red is Tom's favourite colour, things get slightly more complicated when we now turn to questions. What actually does have truth conditions (or is truth-evaluable) is the answer to the question. Roughly put, an affirmative answer is true iff <red is Tom's favourite colour $>$ is true, false otherwise, and vice versa for negative answers. The problem, though, is that if we associate answers in this way with truth conditions, we still do not know the truth conditions for the question itself (for there is none). Even worse, if we take wh-questions into account, we not only do not know the truth conditions for the question itself (as opposed to the corresponding answer); we do not even know how to associate a question with a (set of) proposition(s) at all. As in the case of yes-or-no questions, the theory would need to refer to the answer. But since there are infinitely many (or at least a whole lot of reasonable) answers for specific wh-questions, the theory would need to 'build' truth conditions out of 'the question' and 'the answer' (i.e. the relevant parts thereof). Roughly along the following lines: the answer "Red" to the question "What is Tom's favourite colour?" is true iff red is Tom's favourite colour; the answer "White" to this question is true iff white is Tom's favourite colour; and so on ad libitum. As of today, Davidson-inspired semantics for non-declarative types of sentences still tends to be a rather unsatisfying endeavour.

Ad (i): I have shown that there are good reasons to question the general success of the truth-conditional paradigm. This undermines the plausibility of the second of the two original assumptions. It is now time to turn to the first assumption (meaning is truth condition). Likewise, I shall now demonstrate that this assumption is also unwarranted. Truth conditions are an important aspect of meaning, but only aspects, nevertheless. Many other aspects of meaning are not covered by theories that, like TCS, focus solely on truth conditions. There are even many circumstances in which it seems irrelevant what the truth conditions of sentences are (or the referential 'facts' concerning singular terms, for that matter). 
All different varieties of truth-conditional semantics seem so attractive because of their purity and technical rigour. If the meaning of "snow is white" is that it is true iff snow is white, what else, then, can you ask for, if your main aim is clarity in meaning statements? The concepts employed by TCS are unambiguous: a word " $w$ " either refers to its referent or it does not; a sentence " $s$ " is either true in such-and-such circumstances or it is not; a predicate " $F$ " either denotes a certain set of individuals or it does not; a proposition $<p>$ is either true or it is not. Language is different. Language is vague, not only in regard to a concept like "bald" but in general. Language is, as we have known since Wittgenstein, vague in regard to "chair", for example, which is a term that serves not exactly as a paradigm example in the literature on vagueness. People's disposition to apply "chair" to a given entity develops over time, it varies between individuals, and it is contextdependent. Unlike truth conditions: "This is a chair" is either true or false if applied to a given object, and it is true only if the entity referred to by "this" is actually a chair.

To be sure, sentences seems to wear their truth conditions on their sleeves. That is to say, even if the meaning of "chair" is not a fixed set of individuals (the chairs) but varies with certain contextual factors including time, idiolect, conversational situation, etc., then "This is a chair" is still true iff this is a chair (corrected for time, idiolect, situation, etc.). ${ }^{49}$ So the problem is not epistemological in nature. Rather, the problem is that the only plausible explanation for the varying meaning of "chair" is a corresponding variety of use in speakers. (Neo-)Davidson semantics is strictly bound to the Tarski-style framework summarised above. In this framework, the referents of individual terms and general terms are fixed (as in "'Aristotle" refers to Aristotle"). This implies that, for each new meaning of a term, one would need a new 'base rule' stating its meaning, which amounts to an all new theory. ${ }^{50}$ This is implausible if TCS is put forward as a solution

${ }^{49}$ The theory that most explicitly denies such a stance on truth conditions is called occassionalism (Travis 2008). That is clearly a minority view.

${ }^{50}$ Actually, the underlying problem of formal approaches to semantics is that the meaningdetermining context is particularly wide, as exemplified by Tomasello's 'Tom's bicycle' case (see above). For example, it may include common ground, world knowledge, speaker intentions, etc. Formal approaches may cope with some specific contextual factors such as time, place, and speaker, but it is virtually impossible for them to formally specify 
to the Novelty problem, as it is far easier to assume that people's ability to understand new sentences derives from their implicit knowledge of how the terms occurring in them are used than it is to assume that this ability derives from their learning new theories every now and then.

\subsubsection{Novelty and Usage-Based Theories of Meaning}

The basic idea defended in the present chapter is that compositionality and Novelty are, in effect, two completely distinct issues. In particular, I have argued that the immediate step from Novelty to compositionality is unwarranted, i.e. that the alleged compositionality of natural languages is not the only option when it comes to reasonable solutions to the Novelty problem. In a way, this line of reasoning might seem anti-compositional. Although nowhere in my argument do I presuppose that languages are not compositional, I at least assume that one crucial argument in favour of the compositionality of natural languages fails. Anyway, the received view of how Novelty is to be explained is in terms of compositionality. Hence, denying the alleged strict relation between the two issues eventually leads to a certain tension between the two explanatory needs.

Here is not the right place to formulate a fully fledged alternative to the received view. Rather, I would like to highlight some methodological concerns and roughly indicate a possible solution to the problem just sketched. One potential problem in Davidson's own argumentation seems to be this. From the (apparently correct) observation that people understand any instantiation of a well-formed sentence (of a language that they master), Davidson more or less directly concludes that TCS holds. This line of reasoning essentially relies on the strategy of explaining abilities concerning sentence comprehension in terms of lexical and syntactic capabilities. Crucially, this kind of argument amounts to saying that sentence comprehension involves knowledge of composition rules and recursion. The thing is that this argument as such does not favour TCS nor, in fact, any other theory. An opponent of TCS could perfectly well accept the whole argument (up to this point) and argue that composition rules and recursion might be accounted

contexts in regards to, e.g., the knowledge shared by hearer and speaker. Accordingly, such frameworks would typically emphasise that these 'non-formal' features of context do not affect literally expressed content of sentences (e.g. Borg 2004, 2012). 
for somewhat differently (e.g. in terms of usage-based facts). Which is to say that there is no direct step from the assumption that natural languages are organised recursively to the denial of usage-based semantics.

Another potential problem is that people-for no obvious reason-tend to think that usage-based approaches to semantics are incompatible with the compositionality principle. From this perspective, then, it looks pretty straightforward to directly infer from Novelty that some form or other of truth-conditional semantics must hold. Throughout this book, I continue to distinguish, in terms of the philosophy of language, only between two broadly construed camps: usage-based vs truth-conditional. Although this distinction, as any categorisation in philosophy, simplifies things a bit, I think it is reasonable to suppose that it does not oversimplify. If you buy into this distinction, then the claim that usage-based approaches are incompatible with the compositionality principle amounts to saying that all compositionality-involving explanations (e.g. with regard to Novelty) must be essentially truth-conditional. An example that nicely illustrates this position can be found in Fodor \& Lepore (2002, 3-4):

The line of our argument is that since mental representation and linguistic meaning are de facto compositional, we can reject out of hand any theory that says that concepts//word meanings) are Xs unless Xs are the sorts of things for which compositionality holds. That is, there must be a distinction between primitive and complex Xs, and the syntactic/semantic properties of the latter must be inherited from the syntactic/semantic properties of the former. [...] It's our belief that [...] only very few [candidates]-perhaps only one-can meet this compositionality condition; it's the bull in almost everybody's china shop.

With the above methodological considerations in mind, there are now two theoretical possibilities available to a usage-based theoretician who wants to refute the Davidsonian learnability argument. One option is to deny the assumption that usage-based approaches are incompatible with the compositionality principle. In other words, one could concede the major portion of the argument up to the intermediate conclusion that Novelty can only be explained in terms of composition rules and recursion (or, that 
this at least holds for the majority of cases). Accordingly, one would then need to show that usage-based accounts can be construed compositionally/recursively ${ }^{51}$. There are indeed some explicit attempts to reconcile the compositionality principle with usage-based semantics (e.g. Horwich 1997a). So this seems to be a viable strategy indeed.

A further option is to object to the line of reasoning one step earlier. The way I presented the argument is supposed to show that only Novelty has the status of a phenomenon, which is to say that it is indisputable in a way. It would require some really weird assumptions to describe the objectively observable phenomena in such a way that people, in fact, do not understand each other. Compositionality, on the other hand, is not equally immune; the fact that we typically describe languages as being fully compositional might be an artefact of academic training. Even if some (or most) parts of natural languages are compositional, some might be non-compositional. In effect, Construction Grammar suggests something along these lines. Importantly, in this case the whole learnability argument fails. If people are able to understand some classes of semantically noncompositional complexes (e.g. holophrases, sayings, certain syntactic constructions, idioms, etc.), then, by all means, compositionality can't account for Novelty in the way suggested. This would undermine that argument as a whole, since the point of invoking compositionality considerations is to account for Novelty tout court.

Here I can only very briefly indicate the basic direction that such a strategy would need to take take. In general, the claim that understanding is possible in cases in which the alleged knowledge of recursively defined composition rules plays no role whatsoever can be established quite easily. A highly pertinent example in this context is holophrases:

[...] most children begin language acquisition by learning some unparsed adult expressions as holophrases-such expressions as I-wanna-do-it, Lemme-see, and Where-the-bottle. (Tomasello 2003a, 38)

\footnotetext{
${ }^{51}$ Here, I do not discuss recursiveness and compositionality separately, because the learnability argument itself presupposes that the relevant composition rules get formulated recursively (for otherwise they could not help explaining the human ability to understand an infinity of well-formed expressions).
} 
Holophrases show that phrases that are semantically compositional from the adult's perspective (and are supposedly construed with that knowledge in mind) can be understood by children who lack the relevant syntactic knowledge (in appropriate circumstances, that is). From a philosophical point of view, two questions are especially pressing. What is the relationship between the (non-compositional) understanding of holophrases in children and the (supposedly compositional) rules that adults employ in uttering them? What is it that explains comprehension abilities if not the familiarity with composition rules?

In line with the Tomasellian paradigm, I suggest pursuing the following strategy. As regards the first question, holophrases are particularly interesting in two respects. They not only pose a problem for explanations (of Novelty) that recur to compositionality/recursion. Moreover, they themselves hint at the solution to the problem they pose (if that much metaphor is okay). Let me explain. Postulating knowledge of composition rules is not only the alleged solution to the Novelty problem but elicits further problems: namely the problem that the postulated body of information must be acquired in the first place.

A plausible solution here is to suppose that language learners learn composition rules by experiencing them instantiated. Simply put, the only way for learners to figure out the 'workings' of recursively defined composition rules (e.g. the semantics of relative clauses) is by observing how they are used. Holophrases are a particularly illustrative example in this context because they are interpreted non-compositionally by definition. ${ }^{52} \mathrm{How}^{-}$ ever, the basic mechanism of utterance interpretation is probably alike in all cases of language comprehension. The strategy that gets employed when inferring composition rules from a given set of utterances is, of course, well-known: abstraction (cf. Tomasello 2003a). What mechanism, other than abstraction, could explain language learners' ability to acquire syntactic knowledge ${ }^{53}$ This argument does not even presuppose a specific un-

${ }^{52}$ If you assume that children who understand holophrases apply rules of composition you are either redefining "holophrase" or changing the subject matter.

${ }^{53}$ I mean, supplemented with further constraints. Abstraction per se (whatever that is) does not help here, for one first needs to 'guess' what the relevant entities were relative to which one needs to abstract from contexts of utterance. For example, it helps if you have reasons to suppose that a particular verb is a verb, that a particular noun is a noun, 
derstanding of 'abstraction'; for the purpose of this short section, it suffices to say that abstraction is one's ability to recognise commonalities between contexts and infer generalisations on the basis of this ability.

Remarkably enough, most of the entities that theories of meaning deal with are abstract entities such as propositions, sentence types, lexical meaning, inference rules, conceptual roles, semantic nets, etc. That is remarkable insofar as this coerces language learners to familiarise themselves with abstract entities (e.g. sentence types) by examining concrete objects (e.g. utterances). Given the degree of abstractness that linguistic descriptions have, it is no wonder that people argue about issues like the bottleneck problem (e.g. Kirby 2002), the poverty of the stimulus argument (e.g. Chomsky 1965), language faculty in the broad sense and in the narrow sense (Hauser, Chomsky \& Fitch 2002), e-language and i-language (Chomsky 1986), and the like. More importantly, given that the only available data for learners is utterances (i.e. context-bound instantiations of sentence types), they have no other choice than to use that data to determine the semantics of the abstract entities they are supposed to learn. For example, language learners might infer that "chair" refers to chairs from the observation that most of their already competent interlocutors use "chair" to refer to chairs.

The above argument strongly suggest the following interpretation of language acquisition: rather than relying on knowledge of composition rules in order to interpret utterances, learners seem to do just the opposite. They are forced to acquire linguistic knowledge, including knowledge concerning recursive composition rules, on the basis of their prior understanding of utterances. In this view, the error in explaining Novelty in terms of compositionality lies in the negligence of the fact that the composition rules at hand must be acquired first. As I have shown, the possibilities are rare here. One option is to assume they are innate, which seems implaus-

etc.; it helps if you can narrow down the logical space for novel semantics by taking into account known semantics (Ferguson, Graf \& Waxman 2014); it helps if you are able to delineate word boundaries (Tomasello 2003a, 59-61); it helps if you can tell whether it is a particular (absent) object that your interlocutor is focusing on (Liszkowski, Schäfer, Carpenter \& Tomasello 2009); it helps if you are capable of recognising syntactic structures (Brent 1994); and so on and so forth. 
ible for a variety of reasons. ${ }^{54}$ The alternative is that they are learnt. However, if they are learnt, they are learnt on the basis of the available data. And the source data is utterances, which-from a metatheoretic perspectiveare compositional complexes.

One of the currently most influential neo-Davidsonians, in discussing mindreading abilities, frames the problem thus:

A first point we need to consider concerns how the nascent language user acquires their lexicon initially. That is to say, since presumably normal speakers are not born with a dictionary-like body of knowledge, pairing natural language words with their meanings, we need to explain how competent language users come to learn such information. [...I]n order to learn a language in the first place (for example, to find out which publicly available sign one's linguistic community has chosen to attach to which object or property) it may well be that a grasp of speaker intentions is necessary. [...] Yet all that the modular theory [Fodorian modularism, upon which Borg's Minimalism is based] is committed to claiming is that once this system is in place, that is, once a lexical item has been acquired, then the use of this item no longer need rest on recognition of any kind of speaker intention. (Borg 2004b, 136 and 139, both italics mine)

The problem that Borg discusses here is that there seems to be no place in her theory for intention ascriptions and mindreading abilities. Let us ignore this issue for the moment. I identify at least three important points in the quoted passage. Firstly, Borg acknowledges that although semantics 'takes place', so to speak, at the level of types (in particular, lexical meaning), acquisition of (alleged) semantic facts necessarily takes place at the

\footnotetext{
${ }^{54}$ For example, one insurmountable problem in this context is the speed with which meaning shifts, grammaticalisation processes and the like take place. At both the syntactic and the semantic level, natural languages morph within periods of time that are incompatible with innateness theses. It might be that the processes that constitute language acquisition are innate to a large extent (e.g. things like gaze-following ability; cf. Brooks $\&$ Meltzoff (2005)). Innateness of these processes does not affect the present argument though.
} 
level of tokenings. This is tantamount to saying that language learners face the problem of simultaneously abstracting away from all factors that contribute towards utterance meaning, e.g. from speaker intentions. Secondly, Borg indicates here that she wants to defend a rather naïve conception of the continuity of natural-language semantics. Describing the problem of word learning along the lines of finding out which words 'one's linguistic community has chosen to attach' to particular objects clearly neglects the dynamics of actual language use. I will return to this in a minute.

Thirdly, Borg suggests a strict boundary between semantics and language acquisition. ${ }^{55}$ I think this last point and the second one are, effectively, two sides of the same coin. If you think that word semantics works as if it were written down in a social contract, then you probably also think that word learning processes are completed once they are finished. Such a strict boundary seems unwarranted, given the rapidity with which, for example, words change their meaning in actual linguistic societies. It seems far more plausible to assume instead that the mechanisms underlying language acquisition keep being used even in competent speakers. This picture is, to a surprisingly large extent, congruent with Borg's view; the only difference being that I would assume that language 'acquisition' is not completed at some point but is rather a continuous process. Simply put, word learning-or, in general, learning of new constructionsis a process that happens with each acquaintance with a particular instantiation. It is just that most words have a relatively stable lexical meaning which might invoke the impression that learning processes concerning

${ }^{55}$ In other parts of the book, she also distinguishes between semantics and language use (i.e. communication). This enables her to allow for things like mindreading abilities not only in language acquisition but also in language use, although they are not allowed in her actual theory. That is to say, mindreading abilities (and the like; e.g. plausibility considerations, world knowledge, cotext, default assumptions, etc.) do affect language acquisition and language use, but, in her view, they do not affect semantics proper. For the specific relevance of default assumptions in semantics, the reader may consult the work of Jaszczolt, who says that

Starting with salient meanings of lexical items [...], interlocutors proceed to the interpretation of larger units either assigning meanings to them automatically or processing them through conscious inference, depending on contextual factors. $(2011,14)$

See also Jaszczolt (2005). 
these words are finished at some predefined point in time, i.e. once one had 'found out' which words attach to which objects (cf. the use of "and" today and five-hundred years ago). However, other words change their meaning rather rapidly, which undermines the claim that learning processes regarding them (or, in fact, any other term) can be completed once and for all (cf. the use of "to twitter" today (2014) and ten years ago).

There is one more general worry that I would like to raise in regard to the above quotation. The passage clearly invokes the impression that any specific semantic theory could be reconciled with just about any theory of word learning. The basic idea seems to be that allowing for mindreading (and the like) at the level of acquisition does not affect the plausibility of denying that such capacities play an explanatory role at the level of semantics. Again, '[e]ven if we ultimately decide that language acquisition is an essentially inferential process [...], there is no direct move from this idea to the claim that linguistic understanding per se is such an inferential process [...]' (Borg 2004b, 139, emphases hers). But this seems problematic as the object of the relevant acquisition processes are the abstract entities postulated by semantics (e.g. sentence meaning as opposed to utterance meaning). So the link between the two realms is rather tight. Borg explicitly characterises herself as neo-Davidsonian (2004b, ch. 1, passim). By virtue of this conviction, the basic elements postulated by her theory must concern knowledge of referential relations, for the simple reason that these relations are the defining feature of Davidsonian semantics.

This implies, though, that a theory of word learning (or, generally, an acquisition theory) is compatible with Borg's minimalism only to the extent that the objects postulated by the former theory comply with the objects postulated by the latter theory. I begin with the latter theory (Borg's). Being a neo-Davidsonian approach, the basic elements postulated correspond to the so-called Tarskian 'base clauses' discussed above (“'snow' refers to snow"; " $x$ satisfies 'is white' if and only if $x$ is white"; et cetera). I dub these 'referential facts'. If one combines all this, the following picture emerges. Firstly, Borg herself suggests that word learning can only be explained in terms of use. Secondly, a strict boundary between acquisition theories and semantics seems unwarranted, since 'word learning' is an ongoing process. You can't delineate the class of cases in which you learn from the class of cases in which you merely interpret. Hence, word learning is 
usage-based and it is not clearly separable from mere semantic interpretation. Given this, it seems highly unlikely that the theoretical objects that a theory of language acquisition should postulate are beliefs concerning referential facts rather than beliefs concerning usage-based facts.

This concludes my discussion of the relationship between theories of acquisition and theories of meaning. A related worry that I already raised above concerns relevant alternatives: what kind of explanation accounts for Novelty if not ascription of knowledge about recursive rules of compositions à la Davidson? Here, my answer will be even more tentative (i.e. shorter), as this question actually requires a book-long treatment. I think Davidson's strategy is to combine the two problems reflected in compositionality and what I call Novelty. His proposal, essentially, is to provide a single solution for both issues. Given all the reasons cited above in favour of the distinction, I accordingly suggest that an answer to the question at hand involves distinguishing between these two projects first. That is to say, the alternative explanation we are after primarily concerns Novelty, not compositionality.

Presumably, competent language users construe their utterances partly on the basis of the rules of composition that they master. This, however, does not imply that language learners employ the very same rules in order to interpret those utterances. Nor does it imply that language users employ only those rules in conjunction with lexical knowledge whenever they interpret (for what hearers potentially understand is utterances, not sentences). Which mechanisms play a role in interpretation is, at the end of the day, an empirical question. It thus does not concern me here. Davidson, I think, is quite right in noting that the ability of competent language users to interpret novel 'sentences' is somehow rooted in their prior linguistic understanding. Yet, as the above discussion shows, this does not speak (solely) in favour of his theory. The very same 'correlation' between prior linguistic knowledge and understanding could be explained relative to the assumption that the recursive rules of composition get formulated in usage-based terms. The above argument concerning language acquisition (and the continuous process of 'acquisition' due to the dynamics of natural languages) suggest that, in fact, those rules (as well as lexical knowledge) should be thus formulated. 
The philosophically most relevant point in this context is, I think, that language learning reveals a general constraint on how the Novelty problem should be best approached. Language learners (e.g. children) understand 'novel sentences' just like we do. In contrast to competent speakers, they do this despite their lack of prior linguistic knowledge. In Borg's terms, they do not know yet which expression has been chosen by the society to attach to which object or property. Fortunately, the ascription of understanding is fairly independent from what we suppose constitutes this understanding. Whether we are justified in ascribing understanding concerning a given utterance to a given child in a given situation depends on the overall observable behavioural patterns that the child shows. This is essentially independent from the linguistic knowledge that we typically presuppose in adults. By assumption, children lack this kind of knowledge. Given that, nevertheless, they are able to understand (which is justifiable on the basis of what they do), something else must explain their abilities.

As I said, I will not try to give a comprehensive answer here. The philosophically relevant point is just that whatever one's explanation might be, it can be given independently from the fact that the 'thing' that is supposedly understood (i.e. an utterance) is semantically compositional from the point of view of competent speakers or theoreticians. For example, "Gimme-it!" seems compositional from the adult's perspective. But typical evidence for a child's understanding of that expression would be its satisfaction when it receives the object that it asked for. This holds even if we had independent reason to assume that the child does not understand the underlying compositional structure of the expression (for example, if we knew independently that the it does not understand or apply "give" in other linguistic contexts).

These considerations are essentially methodological. The interesting issue still remains: what explains understanding if not prior linguistic knowledge? The currently by far most influential paradigm in the area of language acquisition is Tomasello's. The basic idea is to shift the theoretical focus from language as such to the social settings in which language takes place. More precisely, the Tomasellian idea-put in philosophical proseis to focus on human cooperative behaviour by viewing language as one means among others that enable or foster cooperation in the first place. In contrast to the Gricean paradigm, language is not conceived as a cooperat- 
ive endeavour but as a means to achieve cooperative goals. ${ }^{56}$ This suggests the direction that a plausible answer to the present question would need to take. A theory of meaning starts with a theory of communication, as communication is the point of having a language. What cognitive agents are primarily interested in is achieving their respective ends. Using language 'correctly' is only interesting insofar as it fosters success in achieving these ends. According to Tomasello, language is basically a means that helps achieving goals in cooperative settings (Tomasello 2008).

When it comes to language acquisition, the question accordingly is not: why do children understand certain utterances? Rather, the relevant question is: by which means do humans achieve cooperative goals in general? Or, rather, what are the prerequisites under which cooperation occurs? Applied to the holophrase example, the idea then is to first explain the prerequisites for the achievement of particular goals (here: 'getting it'). Such an explanation probably recurs to common ground, joint attention, mindreading capacities, and related notions, i.e. notions that are not primarily designed to explain language but cooperation. Semantic explanations would then start, if you like, from the 'communication-theoretic' fact that the child is able to recognise the specific meaning of "Gimme-it!" in particular situations (i.e. in situations that are such that uttering "Gimme-it!" leads to 'getting it'). Generally, approaching language comprehension this way makes it possible to explain the quite counter-intuitive effect that it seems possible to understand utterances without 'understanding' the instantiated sentence type in advance. This is what actually happens in language acquisition. In a final step, the semantic explanation in the strict sense (i.e. explanations concerning lexical and syntactical knowledge ${ }^{57}$ ) presumably recur to the child's abstraction abilities (whose exact nature is, again, an empirical question). For example, in order to acquire knowledge of lexical meanings, a child needs to recognise similarities between the semantic contributions of the same word across different conversational contexts.

${ }^{56}$ This is my supervisor's way of putting it.

${ }^{57}$ Remember that construction grammar-the theoretical framework that serves as a backdrop for this book-assumes that syntactic constructions bear their own meaning, which is why I list them here in the context of semantics. 
